\author{
Maria Laura Osta Vazquez \\ Universidad de Montevideo, Montevideo, Uruguay
}

Alvaro García

Universidad de Montevideo, Montevideo, Uruguay

\title{
Las mujeres y sus espacios: partidos, derechos y debates en el Uruguay de 1920 y 1938
}

\begin{abstract}
Resumen: El presente artículo es una síntesis descriptiva del contexto histórico centrado en las discusiones sobre los diferentes posicionamientos en la aprobación de los derechos políticos de las mujeres en Uruguay de los años 1920 a 1938. A partir de la historia de las mujeres, este estudio tiene como objetivo relatar nuevos discursos históricos donde las mujeres y sus acciones estuvieron representadas en forma equitativa a la historia de los hombres. En el proceso de consolidación de Uruguay como "país modelo" creado bajo la égida del batllismo, se presentaban como principales instrumentos los partidos políticos, que ejercían los cambios en función de sus intereses electorales y políticos específicos. En las discusiones sobre los valores que caracterizaban Uruguay, el tema de los derechos políticos de las mujeres estuvo presente. Los partidos tomaron a las mujeres como objeto político como uno de los ejes de esa consolidación democrática y social.
\end{abstract}

Palabras claves: feminismo; derechos políticos de las mujeres; partidos

\section{A - Uruguay: entre el mito y la realidad durante los años 20}

Los años veinte ven nacer la "Segunda República" en el Uruguay. Fueron tiempos de consolidación de varios cambios que venían procesándose desde el novecientos, donde el batllismo como sector político dominante impulsó a ese "país modelo". En estos años Uruguay "asumió todos los contornos de una sociedad moderna y democrática" (Carlos REAL DE AZÚA, 2000, p.43), donde se consolidó una estructura social que parecía igualitaria, con un Estado que predominaba en las esferas de servicios y empresas públicas con un fuerte criterio distributista. Fue así que las leyes sociales como las jubilaciones y pensiones, la regulación laboral, la educación gratuita en sus tres niveles, una actividad económica

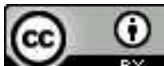

Esta obra está sob licença Creative Commons. 
en crecimiento y las obras públicas que mostraban la magnificencia de un orden democrático liberal, hicieron de este país una sociedad de fuertes vínculos democráticos y sociales.

Esa construcción cultural, económica y política se materializaba en una serie de acontecimientos. En 1923 se inauguraba el monumento a Artigas en la Plaza Independencia. Obra del escultor italiano Ángel Zanelli, la obra sencilla, pero de grandes proporciones, muestra a un Artigas en la principal plaza de la capital, de espaldas a la Ciudad Vieja, mirando a las afueras. Era una reconciliación de Artigas con Montevideo, pero también era una mirada al futuro. El 25 de agosto de 1925, se inauguraba el Palacio Legislativo. De estilo ecléctico, pero de predominio greco latino, el "Templo a las Leyes" se erigía como el lugar de donde provenía la democracia. Era como la acrópolis montevideana, construido en la zona más alta del barrio de la Aguada. Luego, en 1930 se inauguraba el monumento al Gaucho, sobre la avenida 18 de julio. Así culminaba un proceso donde se reconocían a todos los componentes de un orden político que se consolidaba en el Uruguay del Centenario. Según expresan los historiadores Gerardo Caetano y Raúl Jacob: "Artigas, el Palacio Legislativo y el gaucho eran el trípode de toda una construcción ideológica: un pasado que había dividido pero estaba superado, un presente que se construía en orden y en paz" (CAETANO, JACOB 1989, p.15).

A partir de una lectura analítica de la prensa y de las discusiones parlamentarias, se busca analizar las distintas intervenciones que las mujeres han realizado en nuestra historia. Es un artículo descriptivo, que procura resignificar las clásicas lecturas de la historia uruguaya a la luz de la integración del accionar de la otra mitad de la población, casi siempre silenciada. Se propone rescribir la historia a partir de una mirada de la Historia de las Mujeres.

Siguiendo los lineamientos teóricos de la autora Joana Maria Pedro, entendemos que:

...é necessário pensar que pesquisas estamos fazendo na História. Estamos usando esta disciplina para reforçar a heterossexualidade ao considerá-la como a norma? Como estamos observando os discursos da constituição do Estado? O que é generificado nestes discursos? Quais relações são feminilizadas e quais masculinizadas? (Joana Ma. PEDRO, 2005, p. 920).

Se busca cuestionar y resignificar las formas de escribir la historia del Uruguay, donde se invisibiliza a las mujeres como posibles autoras y agentes de cambio en los procesos políticos, económicos y sociales.

En ese proceso de consolidación nacional, los partidos políticos jugaron un rol fundamental. Desde muy temprano en nuestra historia, los partidos adoptaron un carácter central en la integración ciudadana y la formación de una cultura política caracterizada por la construcción de una consciencia nacional. El diputado herrerista Segundo F. Santos decía, en 1929: "Nadie que conozca la psicología nacional, podrá abrigar la ilusión de que en nuestra tierra pueda hacerse nada al margen de los partidos" (CAETANO, Romeo PEREZ, José RILLA, 1987, p.37). Los partidos políticos se manifestaron como los constructores de una tradición histórica, haciendo referencia a sus líderes y sus vínculos con el pasado, las inclusiones de nuevos ciudadanos como los inmigrantes y más adelante, como veremos, las mujeres. Otra característica de los partidos uruguayos fue su policlasismo, lo que sirvió para consolidar una identidad partidaria fiel que, además, integraba a todos los sectores sociales. En los años veinte, la democracia uruguaya se consolidó en torno a los partidos políticos y la resolución de conflictos por la vía electoral, abandonando así las viejas prácticas bélicas que se veían como instancias de un Uruguay bárbaro. Así, "el

2 Revista Estudos Feministas, Florianópolis, 26(2): e48711 
involucramiento ciudadano de la casi totalidad de la población, [...] profundizó el consenso democrático en la sociedad uruguaya al punto de hacerlo casi sinónimo del "ser nacional" (CAETANO, PEREZ, RILLA, 1987, p.37).

La actividad feminista en el Uruguay data de comienzos del siglo XX, cuando los primeros grupos se organizaron a instancias de mujeres de destacada experiencia en la región y el mundo. Las distintas agrupaciones creadas en el Uruguay fuvieron como principal bandera la obtención del sufragio. ${ }^{1}$

En los años veinte, las propuestas y debates de la Alianza Uruguaya de Mujeres no solo plantearon el tema del sufragio: la niñez, la alimentación de las familias más pobres, los hogares para niños cuyas madres fueran trabajadoras, la prostitución y la prevención de enfermedades de transmisión sexual, incluso el desarme y la paz mundial. La propia Paulina Luisi había viajado a La Haya donde se reunía la Sociedad de Naciones, y desde allí intervino en varios debates sobre la estabilidad mundial tras la Gran Guerra.

Los proyectos de ley respecto a los derechos políticos de las mujeres se remontan a 1914, cuando los diputados batllistas Héctor Miranda, Juan Buero, Atilio Narancio y César Miranda presentaron un proyecto a la Cámara de diputados donde se acordaban amplios derechos para que las mujeres fueran electoras y elegibles. Este proyecto no prosperó. En 1917, la Convención Nacional Constituyente discutió el tema de los derechos políticos de las mujeres, pero no llegándose a un acuerdo, ya que el sector anticolegialista compuesto por blancos, católicos y colorados anti batllistas era mayoría, se rechazó. La Comisión encargada de negociar en última instancia la Carta Magna incluyó un artículo por el cual se necesitaban mayorías especiales para introducir los derechos políticos de las mujeres sin necesidad de una reforma constitucional. O sea, que solo mediante la aprobación de una ley con mayorías especiales se lograba incluir el voto de las mujeres en nuestro sistema electoral. El acuerdo simplificaba los mecanismos de ampliación de la ciudadanía, pero no fue por cierto sencillo lograr esas mayorías especiales.

Esa construcción ciudadana venía dándose desde el siglo XIX, donde las lentas transformaciones políticas y sociales generaron - cuando no requirieron casi por imposición externa - cambios en la estructura y organización del Estado. En el Novecientos, un grupo político liderado por José Batlle y Ordóñez cuestionó el orden político, económico y social del Uruguay del siglo XIX. Ese orden englobaba desde el respeto a la propiedad privada, las inversiones británicas predominantes, un nuevo rol del Estado en materia de intervención social y económica y los nuevos roles de los grupos considerados más desprotegidos entre los que se encontraban los obreros y las mujeres. Surgió así el "reformismo", es decir "la tendencia a promover el cambio más o menos radical de los modelos económicos, sociales y mentales dominantes, sin recurrir a la violencia." (BARRÁN, Benjamín NAHUM, 1985, p.13). Esta postura del batllismo llevó a un cierto entendimiento que no careció de críticas y choques con los sindicatos que se consolidaban en ese momento. Los cuestionamientos al orden social, económico y cultural eran similares. La diferencia estaba en las prácticas para lograr cambios más profundos. Los sindicatos, de clara inspiración anarquista, llevaban la crítica menguada a los niveles de enfrentamiento radical. El periódico ácrata quincenal, "La Batalla", dirigido por María Collazo, expresaba:

[...] esos avanzados que creen en el reformismo de Batlle no se olviden tan fácilmente: que si este hombre de Estado pudo implantar alguna ley progresista, es porque los gladiadores de todos los países, desde hace años, vienen sacando del camino, los grandes escombros que obstruían el paso, y que nuestro deber, entonces, en continuar como hasta hoy, combatiendo los obstáculos más grandes, dejando los pequeños

' En 1916 se había creado el Consejo Nacional de Mujeres y en 1919 la Alianza pro Sufragio Femenino. 
efectos para los tímidos, para los que se conforman con pequeñeces con tal de no molestar mucho. ${ }^{2}$

El discurso batllista pone en tela de juicio muchas de las estructuras tradicionales, llevando a una reacción por parte de los "conservadores". ${ }^{3}$ Los dirigentes que se veían atacados por el discurso cuestionador del batllismo comenzaron a crear una dicotomía diferente en torno a la tradicional división de explotados y explotadores.

La ampliación de la participación y la consolidación de espacios de discusión en la década del veinte tuvieron también como tema el rol político de las mujeres. El mundo presenciaba cómo lentamente las mujeres tomaban participación activa en diversos debates sobre derechos políticos, sociales, laborales, empeñándose por conquistar espacios en la arena pública que la convirtieran en protagonista.

Los años veinte se vieron marcados por un resurgimiento de los temas feministas en la agenda pública tras el debate iniciado en 1916, cuando se incluyó la posibilidad - que luego resultaría fallida - de otorgar los derechos políticos a las mujeres. ¿Por qué el tema de las mujeres y sus derechos se instaló en la agenda de los años veinte? A nivel mundial, la Gran Guerra (1914-1918) marcó un hito importante en la relación entre los sexos. La opinión general que se ha instalado es que, ante la movilización masiva de hombres para los ejércitos, las mujeres fueron movilizadas pero como mano de obra, ya sea en las fábricas como en los hospitales. Eran imprescindibles para lograr el aprovisionamiento de los ejércitos - sea de alimentos o de armamentos -, a la vez que se la empleaba en los servicios públicos o en trabajos de mantenimiento urbano. La tarea en los hospitales era fundamental, tomando en cuenta la alta demanda producto de los heridos de guerra. Es así que las mujeres tomaron un protagonismo clave en la vida pública como agentes dinámicos en el mantenimiento del statu quo económico y social. Esta participación derivó muchas veces en la movilización de sindicatos de mujeres que reclamaban salarios más justos y que se les reconocieran los mismos derechos laborales que los hombres. Empezaba a verse el empoderamiento de las mujeres en áreas donde había intervenido de manera secundaria. Sin embargo, algunos historiadores han puesto en tela de juicio ese protagonismo de las mujeres, minimizando los alcances liberalizadores que la guerra trajo. Lo que al principio parecía instalarse en los discursos y las prácticas, respondía más a la necesidad de las industrias y los países por mano de obra que a los cambios culturales y sociales que implicaba admitir el protagonismo de las mujeres e incluso su igualación frente a los hombres. Cuando la guerra terminó y los hombres comenzaron a regresar a sus casas y sus trabajos, la situación parecía volver a la normalidad. De esta manera, "Para las mujeres [...], ha llegado el momento de hacerse a un lado. Se las tacha de oportunistas y muchas veces, de incapaces, y se les pide, en nombre del derecho de los Ex Combatientes, en nombre de la reconstrucción nacional y de la defensa de la raza, que vuelvan a sus casas y oficios femeninos" (Georges DUBY, Michelle PERROT, 1993, p.74). Es cierto que habría que analizar a cada país para explicar un fenómeno tan complejo como este. Muchos países en los años veinte instalaron el debate y las mujeres lograron derechos políticos. Tal vez los dos países más relevantes fueron la Alemania de Weimar y Gran Bretaña. Sin embargo, la protección social y laboral para los millones de mujeres desempleadas no estuvo prevista, y el final de la guerra significó "reinstalar, a la mayor brevedad posible, un mercado de

${ }^{2}$ La Batalla, Segunda Quincena de enero de 1917, p.2

${ }_{3}^{3}$ Cuando mencionamos el término conservador nos remitimos a la definición histórica del historiador José Pedro Barrán. Para él: "El pensamiento conservador en materia política y social puede ser identificado con la defensa del orden establecido, la crítica a los que promueven su reforma y la diabolización de los que bregan por su modificación violenta" (BARRÁN, 2004, p. 11)

4 Revista Estudos Feministas, Florianópolis, 26(2): e48711 
trabajo sexualmente diferenciado, así como a restaurar las familias tradicionales, en las que el padre provea el sustento y la madre se ocupe del hogar" (DUBY, PERROT, 1993, p.74). La vuelta de los combatientes generó nuevas discusiones en relación al trabajo femenino y los derechos laborales de estas.

En Uruguay, los debates de esta índole no fueron ajenos. Algunos diarios publicaron artículos sobre el tema e incluso realizaron encuestas entre conocidos intelectuales para difundir su opinión sobre un tema que estaba en el tapete. La revista "Mundo Uruguayo" publicaba un artículo titulado "Adelantos", sobre la posibilidad de que las mujeres pudieran ingresar a los bares y cafés sin ser objeto de censura por parte de los hombres que en sus mesas se encontraban:

Grata visión la que ofrecen algunos cafés donde la moda ha dado en la idea de reunir señoras y caballeros en derredor de las mismas mesas. Hora era ya de que los cafés perdieran el desolador aspecto de una taberna donde se va exclusivamente a beber [...] En cambio, la moda nueva que ha entrado en algunos cafés, mezclando las mesitas con familias a las de señoras solas y hombres solos [...] el café no es un sitio donde pueda darse rienda suelta a frases y modales improvistos. Es un sitio de expansión y recreo, donde debe reinar la educación y el buen comportamiento que haga la estancia agradable y den deseos de repetir la visita. ${ }^{4}$

Ese Uruguay que llegaba al centenario de la declaratoria de la independencia se ufanaba de los adelantos culturales que tenía. Daba lugar a la posibilidad de que mujeres solas se congregaran en un café con los hombres sin mayores problemas. El café se mostraba como un microcosmos de ese país que integraba y reunía a los más diversos personajes en los mismos lugares; integraba a los inmigrantes, a las clases sociales y a las minorías otrora desplazadas como las mujeres. ¿No era la sociedad hiperintegrada la que se representaba en el café? Se agrega otro detalle a esta descripción: el café era también un espacio de buena educación. Aquella educación que, como joven república, habíamos cultivado en el Uruguay batllista e hiperintegrado, se reflejaba en espacios cotidianos. La visión del café como lugar donde se iba exclusivamente a beber generaba la impresión de que era el núcleo del problema del alcoholismo. Este tema, tratado por los ámbitos políticos y uno de los puntos de atención de las agrupaciones feministas, generó amplios debates. Según la lógica del artículo, si las mujeres estaban presentes en el café, se eliminaría este problema. Al menos parecía mitigar la imagen negativa del café como centro de vicios y problemas. Las mujeres se ven como representantes de una nueva moral que las diferenciaba de los hombres.

Sin embargo, no todos parecían sentirse muy cómodos con estos cambios que se estaban promoviendo. El diario católico "El Bien Público" marcaba sus diferencias distinguiendo al movimiento feminista del "masculinista". Según el articulista, el feminismo "consiste en apreciar las condiciones propias de la mujer, comprender la profunda dignidad de la misión social y la utilidad enorme de sus admirables sacrificios". ${ }^{5}$ El "masculinismo" era "la moneda falsa del feminismo y consiste en [...] creer que la mujer ha vivido en una condición humillante, mientras no ha emulado [...] al hombre. Que la mujer necesita una redención después de muchos siglos. [...] esta redención [...] se realiza cuando la mujer abandona el hogar, sale a la calle, interviene en la política, fuma y va al club [...]".6 Equiparar a la mujer en derechos y roles equivalía a negar su rol o misión social fundamental. El artículo remata la reflexión diciendo que "para dignificar a la mujer hay que

${ }^{4}$ Mundo Uruguayo, 23 de julio de 1925, p. 1.

${ }^{5}$ El Bien Público, 26 de noviembre de 1932, p. 1.

${ }^{6}$ El Bien Público, 26 de noviembre de 1932, p. 1. 
masculinizarla".7 ¿Cuál era el rol de las mujeres según este artículo? El rol social de las mujeres debía ser el del hogar, el cuidado de hijos y sometida a la autoridad del hombre. No le correspondía así estar en la calle o frecuentar los mismos lugares que se consideraban masculinos. ${ }^{8}$

En 1921, el diario "El País" realizó una encuesta entre personalidades intelectuales del momento. Algunos comentarios refutaban claramente los debates en torno a los derechos políticos y a esos espacios que las mujeres estaban ganando en el terreno público. José Irureta Goyena, abogado y representante de los sectores empresariales más conservadores establecía que:

Si la mujer pide amplitud de fueros para hacer las mismas cosas que el hombre, comete un error, porque la mujer efectúa mal y con ahogo lo que el hombre realiza bien y sin fatiga [...]. El hombre no es superior a la mujer, ni la mujer al hombre; el primero tiene cualidades que le faltan a la última; la última posee virtudes de que carece el primero: la fuerza de la especie no consiste en despertar en cada sexo las virtudes ausentes, sino en exaltar las ingénitas, pugnando porque el hombre sea cada vez más hombre y la mujer más mujer por el sentimiento y por la acción. ${ }^{9}$

El político blanco Daniel Muñoz expresaba: "Llamar feminismo a la moderna tendencia de la mujer a desviarse del carril en que su propia naturaleza la ha colocado, es simplemente un contrasentido pues la verdadera denominación que corresponde a esa desviación absurda es la del machonismo".10

Tanto en la opinión de Irureta Goyena como en la de Daniel Muñoz, se desprenden argumentos de "orden natural": los roles de hombres y mujeres se estipulaban de acuerdo a esa selección que la naturaleza había hecho. Los reclamos de los sectores feministas alteraban ese orden natural vigente.

\section{B - La influencia del batllismo y la consolidación de la ciudadanía universal durante la década del 30}

Los años treinta se inician con la peor crisis económica registrada hasta ese momento por el capitalismo. En Uruguay, la crisis no sería la excepción, trayendo además la primera dictadura y con ella las aspiraciones del país de ser una isla en el convulsionado continente americano.

Suele establecerse que entre 1903 y 1930 es la época del batllismo y de su líder José Batlle y Ordóñez como figura principal. Es cierto que su liderazgo fue indiscutido y trascendió su muerte, acaecida el 20 de octubre de 1929, pero en términos electorales el sector batllista fue derrotado en 1916. Fue en las elecciones del 30 de julio de ese año que se votaba la formación de una Asamblea Constituyente, la cual tendría el cometido de reformar la constitución. En esa instancia no solo se votaba a los representantes de esa Asamblea, sino que se cuestionaba el proyecto de Batlle. Tras esas elecciones que el batllismo pierde, el

${ }^{7}$ El Bien Público, 26 de noviembre de 1932, p. 1.

${ }^{8} \mathrm{~A}$ propósito de la postura católica sobre el rol social y político de las mujeres es interesante señalar que no hubo una única postura. Existieron diversas opiniones, como por ejemplo en el periódico "El Demócrata" donde se manifestaron voces a favor de los derechos políticos: "[...] ¿por qué no han de votar las mujeres? [...] ¿por qué van a ser excluidas de esa función [...] la de constituir los poderes del Estado? [...] no depende de nosotros detener el curso de los sucesos." (El Demócrata, 20 de febrero de 1919). El propio Arzobispo de Montevideo, Mariano Soler, se manifestó favorable. Para ver esto: CAETANO; GEYMONAT, 1997. También ver: OSTA, 2008, p. 84-94.

${ }^{9}$ El País, 5 de julio de 1921, p.3.

${ }^{10}$ El País, 5 de julio de 1921, p.3.

6 Revista Estudos Feministas, Florianópolis, 26(2): e48711 
plan político de Batlle giró en torno a tres pilares fundamentales: "[...] la aceptación del "alto" a las reformas ante el temor del retroceso; la búsqueda de "amortiguación" de la imagen reformista del partido buscando ganar el electorado moderado [...] y [...] la apuesta al acuerdo con los "partidos colorados" como única vía posible para evitar la victoria nacionalista" (CAETANO, 1993, p.73). Es cierto que si bien no hubo retrocesos en materia de legislación social, económica y cultural, las negociaciones que tuvo que hacer con los sectores conservadores del propio Partido Colorado lo llevaron a conformarse con mantener el poder, resignando proyectos y lugares en la administración pública.

La muerte de Batlle trajo aparejado no solo la desorganización propia de un partido centralizado en la figura indiscutible de un líder, sino las complejas negociaciones por las candidaturas a la presidencia y al Consejo Nacional de Administración. El ejercicio cívico que representaba el sistema electoral uruguayo hacía que los partidos se enfrascaran casi de manera continua en las discusiones por los lugares en las listas y los repartos de cargos. Fue así que surgió la figura de Gabriel Terra, tal vez el batllista menos ortodoxo de todos por las críticas que realizó a la figura de Batlle durante su vida. Terra ocupó los cargos de legislador, ministro, embajador, constituyente, miembro del Consejo Nacional de Administración. La compleja interna colorada demostraba que la correlación de fuerzas dentro del Partido e incluso dentro del propio batllismo dependía del arbitrio de su jefe civil, ahora desaparecido.

En ese Uruguay republicano y partidocéntrico, la izquierda también marcó su espacio. Si bien era minoría en un sistema bipartidista marcado por el tradicionalismo entre blancos y colorados, el partido Socialista y después el Comunista, fuertemente influenciados por los inmigrantes, se hacían un lugar en la arena políica.

La conformación del Partido Comunista responde, en primer lugar, al triunfo de la Revolución Rusa en 1917. Tras la creación del primer estado proletario, se reunió en Moscú el Comintern, conocida como la III Internacional. Era el año 1919, y tras el fin de la Gran Guerra y la consolidación de la revolución bolchevique, el mundo se estaba preparando para ver nacer un partido de características internacionales. El Uruguay no era ajeno a estos sucesos.

En setiembre de 1920, un sector mayoritario de socialistas decide adherir a la III Internacional y a sus 21 puntos, uno de los cuales establecía que los Partidos Socialistas cambiarían su denominación a Partidos Comunistas y se afiliarían a los principios marxistas leninistas de la revolución de octubre. La discusión más importante "[...] fueron fundamentalmente tácticas" (Fernando LÓPEZ D'ALESSANDRO, 1992, p. 197).

El grupo minoritario del congreso socialista liderado por el Doctor Emilio Frugoni y Líber Troitiño se va derivando hacia la socialdemocracia. Frugoni "creía que la Comintern imponía a los partidos adherentes "normas de conducta (...) reñidas con las necesidades y características de nuestro medio y la propia naturaleza interna de nuestra organización [...]" (LÓPEZ D'ALESSANDRO, 1992, p. 197). Este proceso que ocurrió en el Uruguay fue similar en casi todos los países en que se desarrollaron estas discusiones. Finalmente, el 21 de setiembre de 1920, el $8^{\circ}$ Congreso del Partido Socialista decidió, por 1297 votos a favor, 175 en contra y 275 abstenciones, incorporarse a la III Internacional, creando así el Partido Comunista del Uruguay.

De ahí en más, el Partido Socialista y el Partido Comunista rivalizaron no solo por la disputa del electorado, sino por las ideas de izquierda. La dialéctica discursiva entre ambos se desarrolló en las cámaras legislativas y en la prensa.

La izquierda tampoco estuvo ausente de los debates en torno a los derechos políticos y nuevos roles que la mujer debía tener. El diario comunista "Justicia" hizo hincapié en este aspecto, donde puede notarse cierto signo clasista y combativo de las otras tendencias 
dentro del feminismo uruguayo, al cual se lo calificaba de "burgués". En 1923, el periódico oficial del Partido Comunista del Uruguay decía: "Encontramos en las actividades de las feministas burguesas el elemento estéril y contraproducente que es la lucha por la obtención de los derechos políticos." "I Se partía de la ineficacia de la lucha por los derechos políticos, siendo estos innecesarios para las mujeres que necesitaban obtener otros derechos como los sociales y laborales. Los comunistas consideraban que las instituciones feministas eran "[...] entidades aristocráticas - por aristocracia de clase o por aristocracia intelectual -, pero alejadas de la verdad, del proletariado manual con el que buscan mayores puntos de contacto, hurtándose así a una labor que justificaría su existencia". ${ }^{12}$ En 1924, la prédica de "Justicia" seguía en contra de las aspiraciones de la Alianza pro Sufragio Femenino. Catalogando el principal reclamo de esta agrupación como de mínima y burguesa, sus reclamos eran superficiales, ya que "Ninguna actividad liberadora - por más inteligente que sea - podrá, en la sociedad capitalista, evitar que la mujer esté sujeta a tal dependencia". De esta manera, los derechos políticos no podrán "redimir a la mujer trabajadora de su esclavitud". ${ }^{13}$ Los comunistas uruguayos afirmaban su "fe en la liberación de la mujer obtenida sólo a condición del cambio de régimen". ${ }^{14}$ El Uruguay de este período no estaba preparado para cambios drásticos, reafirmando así su carácter de país avanzado en tanto estaban en el centro los principales temas que todos los países planteaban, pero que los cambios vendrían de forma gradual. La aspiración inicial para la Alianza pro Sufragio era el voto de las mujeres, como el primer escalón. Luego de su obtención vendrían otras aspiraciones que servirían "para llenar ampliamente la vida material y moral" ${ }^{15}$ de las mujeres.

Las elecciones de noviembre de 1930 marcaron un nuevo triunfo para el Partido Colorado. El Dr. Gabriel Terra consiguió mantener al partido en el poder frente a su tradicional adversario blanco, logrando consolidar al batllismo como fuerza gobernante.

Para el Partido Nacional, la derrota no solo marcó una nueva caída para el Dr. Luis Alberto de Herrera, sino que precipitó una crisis interna que culminará dividiéndolo. La Convención Nacionalista de enero de 1931 separará las aguas, creándose el Partido Nacional Independiente con aquellos dirigentes que cuestionaron el liderazgo de Herrera.

La dinámica electoral se desarrolló en un clima económico nada favorable en el Uruguay y en el mundo. El 24 de octubre de 1929 la Bolsa de Nueva York había quebrado, y con ella se sumía a la dependiente economía europea en un ciclo de caídas empresariales como no se recordaba en la historia económica mundial.

En plena celebración del Centenario, los uruguayos comenzaron a sentir los efectos de esa crisis. Se empezaba a alterar así la situación nacional marcada por: "La apariencia de una economía sana, asentada en una moneda sólida y en altos niveles de consumo, la persistente estabilidad de sus instituciones políticas, y aún las recientes hazañas deportivas, alentaban un extendido sentimiento de bienestar a menudo subrayado por los medios inversores extranjeros." (Juan ODDONE, 1990, p. 28). Pese al optimismo, el país no podía escapar a la realidad mundial. La dependencia con los centros económicos mundiales era evidente en las estadísticas: "El principal cliente del país en el quinquenio 1926-1930 fue Gran Bretaña, que adquirió el $28,9 \%$ de la producción uruguaya. El primer proveedor en cambio era Estados Unidos, que concentró el $29,1 \%$ de las adquisiciones uruguayas" (CAETANO, JACOB, 1989, p.25). Dada esta situación, la crisis no se haría esperar. La doble

${ }^{11}$ Justicia, 15 de enero de 1923, p. 4.

${ }^{12}$ Justicia, 15 de enero de 1923, p. 4.

${ }^{13}$ Justicia, 14 de enero de 1924, p.2.

${ }^{14}$ Justicia, 14 de enero de 1924, p.2.

${ }^{15}$ Justicia, 14 de enero de 1924, p.2. 
condición de exportador de materias primas y de importador de bienes de capital hacía que la balanza de pagos fuera deficitaria, sumando además el gran endeudamiento acumulado desde décadas. Con esto, comenzaban a verse las primeras manifestaciones de la crisis: saldos negativos de la balanza comercial, depreciación de la moneda respecto a las divisas extranjeras, déficit en la recaudación fiscal del Estado. La contracción de los mercados internacionales más importantes generó un retroceso de nuestras exportaciones. Así fue como el comercio de carnes enfriadas a Inglaterra en 1931 había caído un 50\%. Las políticas proteccionistas aplicadas por Europa y especialmente los acuerdos de Ottawa firmados entre Inglaterra y sus colonias y ex colonias otorgándole a esta preferencia imperial sobre la importación de materias primas - en muchos casos las mismas que producía Uruguay -, generó una reducción de la producción pecuaria nacional a la vez que los frigoríficos, carentes de materias primas comenzaron a reducir su plantilla de trabajadores. Ese proceso de crecimiento que Uruguay experimentó desde el último cuarto del siglo XIX sustentando en el modelo agroexportador, parecía resquebrajarse.

La crisis llevó a los sectores empresariales a organizarse y ejercer presión sobre el gobierno batllista. Tras las elecciones de 1930, los batllistas resultaron fortalecidos desde el punto de vista electoral. Habían obtenido, además de la presidencia de la República, los seis cargos mayoritarios en el Consejo Nacional de Administración, y habían realizado una estratégica alianza política con los Nacionalistas Independientes, sector, como dijimos, opositor al herrerismo. A esto se sumaba una política de fuerte intervención estatal, por la cual se empieza lentamente a controlar la importación de productos, fijar el valor del tipo de cambio, perjudicando a los sectores empresariales y estableciendo fuertes restricciones a las transferencias monetarias al exterior por parte de bancos y empresas privadas. El Estado aumentaba su acción empresarial, creando en 1931 la Administración de Combustibles, Alcohol y Portland y nacionalizando los teléfonos en 1932. Es así que el capital extranjero, los inversores y las clases propietarias de campos comienzan a organizarse.

Ya en 1929, ante un posible colapso económico mundial y previendo una agresiva política estatista por parte del batllismo, las principales cámaras empresariales conformaron lo que se denominó el Comité de Vigilancia Económica. Esta institución, conformada por todos los grupos de presión económicos, entre los que se destacaron la Asociación y Federación Rural, la Cámara de Industrias, la Unión de Exportadores y la Unión de Bancos, se unieron a los efectos de hacer de sus reclamos verdadera bandera de principios y tener así mayor capacidad de presión frente al gobierno y a los partidos políticos más conservadores. Muchos integrantes de los partidos eran de hecho miembros de alguna de esas cámaras por ser, en sus ámbitos privados, empresarios o vinculados a algunas empresas.

Los acuerdos políticos entre batllistas y blancos independientes también sirvieron para lograr, el 15 de diciembre de 1932, la aprobación de la tan discutida ley que aseguraba los derechos políticos para las mujeres.

Muchas son las causas que se han expuesto respecto a la aprobación de los derechos políticos de las mujeres en Uruguay. La historiografía se divide en dos posturas al respecto de la aprobación legislativa, los que dicen que se relaciona a la incidencia de los partidos y sus necesidades electorales coyunturales, y los que sostienen que las conquistas políticas de las mujeres provienen de una larga lucha que el feminismo militante logró tras casi veinte años de activismo incansable. Es cierto que en el Uruguay poco se podía hacer fuera de los partidos políiticos. Pero, ies posible pensar que las mujeres militantes del feminismo pensaban que solas podían lograr obtener los derechos políiticos? Se parte de la afirmación de que tanto los partidos como las feministas actuaron concomitantemente, como afirman Silvia Rodríguez Villamil y Graciela Sapriza (1984), "No parece [...] casual que el Consejo Nacional de Mujeres se haya fundado precisamente en 1916, cuando se realizaban las elecciones 
para la Asamblea Nacional Constituyente y todo el ambiente político se veía conmovido por las perspectivas de una nueva Constitución."16 En 1930, cuando los partidos retoman la discusión por los derechos políticos de las mujeres, la coyuntura política y económica no les era favorable a sus intereses electorales. Tanto colorados como blancos presentaron proyectos a favor del voto femenino. Es así que los partidos "[...] contaron con aumentar su popularidad mediante una reforma liberal en tiempos de inseguridad financiera" (Asunción LAVRIN, 2005, p.426). El voto femenino resultaba redituable para distraer la atención pública de los problemas económicos que afrontaba el país, a la vez que lograba reunir un electorado cautivo que podía dotar a los alicaídos partidos de mayores apoyos. No es menos importante el hecho de que se llevaran adelante por aquellos años diversas conferencias internacionales a favor del derecho al voto femenino.

En 1930, el diputado batllista Alfeo Brum propuso un proyecto de ley relativo a los derechos políticos y civiles de las mujeres, redactado por su hermano, el ex presidente Baltasar Brum. El proyecto, como todos los anteriores, naufragó en la comisión de legislación de la Cámara de Representantes. En 1931, un grupo de diputados herreristas presentaron una serie de enmiendas constitucionales que otorgaban, entre otras cosas, el derecho al voto de las mujeres. El herrerismo se sumaba así a los proyectos de aprobación de los derechos políticos femeninos, en un claro giro a su postura contraria en 1917, cuando la Asamblea Constituyente discutió la reforma constitucional. Finalmente, en agosto de 1932, los senadores batllistas Pablo María Mibelli y Lorenzo Batlle Pacheco presentaron nuevamente el proyecto, culminando el proceso de aprobación por la Cámara de Representantes el 14 de diciembre de ese mismo año. El batllismo asumía como propio el proyecto y la aprobación del mismo:

[...] El noble postulado de reivindicar los derechos de la mujer figura desde muchos años atrás en el programa del Batllismo y como todas las grandes ideas de ese programa proviene de aquel incomparable espíritu que aseguró para el país la felicidad del presente y elaboró la grandiosidad del futuro, ideas que lentamente irán imponiéndose en su totalidad sembrando de acontecimientos felices la vida del Uruguay (LAVRIN, 2005, p. 426).

El 18 de diciembre reafirmaba "El Día" sus diatribas sobre el voto a la mujer: "El triunfo del voto femenino es la consecuencia lógica de la constante acción del batllismo, que ama la democracia y cree en ella por lo mismo que ha surgido de su seno como una plasmación de las aspiraciones colectivas y de las ansias de mejoramiento y de justicia que forman el anhelo popular". ${ }^{17}$

No fue solo el batllismo el que elaboró un discurso por el cual se apropiaban de la autoría del derecho al voto femenino. Todos los partidos involucrados en la discusión parlamentaria sustentaron sus argumentos en los adelantos que la mujer tenía y los acuerdos que siempre habían tenido con su participación en la vida política. No se detendrá en el análisis pormenorizado del debate, pero parece interesante rescatar algunos pasajes para demostrar esa construcción discursiva que los partidos hacían de sus aspiraciones respecto a la participación femenina en la política, muchas veces no exentas de contradicciones. Por ejemplo, el diputado herrerista Alonso Montaño expresaba: "Los tiempos que corren nos demuestran que ya hace mucho tiempo que la mujer ha dejado de ser la muñeca del hogar. La mujer es la colaboradora en la lucha económica, la que acompaña al hombre en sus desvelos [...]. Está perfectamente preparada [...] para votar.".$^{18}$ El diputado Secco Illa, de la Unión Cívica, votó afirmativamente el proyecto de ley siendo "[...] producto de un

${ }^{16}$ Hoy es Historia, (junio-julio 1984), p. 26.

${ }_{17}$ El Día, 18 de diciembre de 1932, p.7.

${ }^{18}$ Diario de Sesiones de la Cámara de Representantes, Sesión del 14 y 15 de diciembre de 1932. 
íntimo convencimiento compartido desde el nacimiento de nuestra agrupación ciudadana". ${ }^{19}$ Si bien los católicos variaron sus posturas respecto al voto de las mujeres, la Unión Cívica se manifestó contraria al voto de las mujeres cuando esto se discutió en la constituyente de 1916. El diputado cívico establecía que "Lo votamos por íntimo convencimiento, porque entendemos que, dada la estructura social de nuestra sociedad contemporánea, a base de sufragio universal e individual y en donde la mujer es un elemento colocado en el mismo plano que el hombre [...]". ${ }^{20}$

El diputado socialista Líber Troitiño argumentaba su voto afirmativo en que los socialistas eran:

[...] consecuentes con la prédica, con las aspiraciones y con el mandato del Partido Socialista. Y al votar por el reconocimiento de estos derechos, hacemos votos para que él sirva para modificar la estructura de nuestros partidos políticos [...]. Hacemos votos [...] porque la intervención del sufragio femenino [...] de un nuevo contenido a la política nacional orientándola hacia los grandes postulados de solidaridad y justicia social. ${ }^{21}$

El diputado herrerista Eduardo Víctor Haedo, argumentaba su voto afirmativo de una manera original. En vez de construir una historia partidaria del voto femenino, este situó como protagonista de este logro a las propias mujeres. Decía: "Este proyecto es una conquista de la opinión pública [...] es una conquista, pura y exclusivamente [...] de las mujeres". Incluso le pone el nombre de "[...] Paulina Luisi, a quien habrá que recordar en este instante como la mayor precursora de esa magnífica conquista del sufragio femenino". ${ }^{22}$ ¿Qué buscaba Haedo sacando a su partido del protagonismo y poniendo a las propias mujeres como creadoras de las conquistas obtenidas? Podemos pensar que en el diputado blanco tenía convencimiento de que el movimiento feminista fue el protagonista de estos logros. Sin embargo, es cierto también que Haedo pertenecía al principal partido de la oposición y éste se había opuesto al voto de las mujeres en las instancias que se había puesto en discusión. Sin embargo, con habilidad política y retórica, Haedo pone a Paulina Luisi como protagonista, socialista pero sin militancia, un símbolo internacional para el movimiento feminista uruguayo, pero no era la única mujer comprometida. El problema es que las otras mujeres integrantes del movimiento feminista tenían vínculos estrechos con los partidos, principalmente el Colorado y especialmente con el batllismo, enemigo acérrimo del herrerismo al que pertenecía Haedo. Continuaba afirmando el legislador: "[... l la conquista del voto femenino, no es una conquista que se deba a ningún partido político, ni a ningún hombre público: se lo ha ganado legítimamente la mujer; se lo ha ganado en el taller, se lo ha ganado en la fábrica, se lo ha ganado en la Universidad". ${ }^{23}$

No todos los legisladores estuvieron de acuerdo con otorgarles a las mujeres el derecho al voto. Evidentemente no primó en ellos la disciplina partidaria. Una muestra de ello fue la argumentación contraria del diputado blanco Cecilio Arrarte Corbo:

[...] desearía ver a la mujer de mi país como deseo ver a la mujer en mi casa: la quiero ver mujer útil, mujer pundonorosa, delicada y prístina dentro de las tareas domésticas, dentro de sus funciones maternales [...]: pero, [...] no deseo [...] ver a la mujer de mi país, como no deseo ver [...] a la mujer de mi casa, intervenir activamente en las luchas políticas y en las luchas cívicas que [...] llegan hasta molestar el alma y el sentimiento de los hombres [...] mucho más hechos a las crudezas y a las amarguras. ${ }^{24}$

\footnotetext{
${ }_{19}$ Diario de Sesiones de la Cámara de Representantes, Sesión del 14 y 15 de diciembre de 1932, p. 127.

${ }^{20}$ Diario de Sesiones de la Cámara de Representantes, Sesión del 14 y 15 de diciembre de 1932, p. 127.

${ }^{21}$ Diario de Sesiones de la Cámara de Representantes, Sesión del 14 y 15 de diciembre de 1932, p. 129.

22 Diario de Sesiones de la Cámara de Representantes, Sesión del 14 y 15 de diciembre de 1932, p. 131.

${ }^{23}$ Diario de Sesiones de la Cámara de Representantes, Sesión del 14 y 15 de diciembre de 1932.

${ }^{24}$ Diario de Sesiones de la Cámara de Representantes, Sesión del 14 y 15 de diciembre de 1932, p. $135-136$.
} 
En este argumento se visualizan algunos aspectos para analizar: se busca conservar el orden familiar tradicional, donde las mujeres debían estar en la casa al cuidado del hogar y los hombres en el espacio público, siendo los sostenedores económicos de la casa, y así mantener el estatus de pater familias que lo llevaba a mantener el rol dominante. También hay un aspecto moral que siempre fue un elemento a tener en cuenta en las diferencias entre hombres y mujeres: las mujeres eran más débiles, con espíritus mucho más sensibles y poco acostumbrados a las durezas de la vida pública. La política era una actividad que desarrollaba sentimientos duros y por tanto se necesitaba un estado espiritual diferente. Las mujeres políticas perderían así sensibilidad, necesaria para el cuidado de los hijos, de la casa y del marido. Era también un argumento que evidenciaba la intención de mantener el statu quo y con ello el poder. Es decir, lo que los hombres querían era no perder aquellos espacios que ocupaban en exclusividad.

Siguiendo la línea de la oposición a los derechos políticos de las mujeres, se presenta la poetisa intelectual de la época, Juana de lbarbourou, quien escribió un artículo en la revista "Mundo Uruguayo" donde daba su opinión sobre los derechos políticos de las mujeres y su rol social. Para "Juana de América" con la equiparación de derechos civiles y políticos de las mujeres que se estaban viendo en varios países de Europa:

El equilibrio de la familia va a romperse irremediablemente. El contrapeso del hombre luchando fuera de la casa, era la mujer luchando dentro de la casa. El contrapeso del hombre, necesariamente librado de la vigilancia íntima y constante de los hijos, era el de la madre dedicada a ellos. La armonía en la eterna ley de las compensaciones nos llegaba por los hábitos de la lucha y conquista de él, junto con el ejercicio de las virtudes menores (paciencia, dulzura, espíritu de sacrificio) de ella. ${ }^{25}$

La opinión de Juana de lbarbourou partía del argumento tradicional del equilibrio entre hombres y mujeres. Ambos debían estar separados con funciones distintas que supuestamente complementaban la vida familiar. Los hombres en el espacio público y las mujeres en el privado, servían de equilibrio perfecto para un orden familiar y social que no se alteraba. La sociedad era una suerte de máquina, donde "[...] cada pieza desempeña su cometido. Si todas anduvieran en un mismo sentido y con iguales movimientos la máquina se rompería. ${ }^{26}$ Esta referencia modernista de la sociedad, equiparándola con una máquina, no oculta un sentimiento conservador que buscaba preservar las estructuras tradicionales que venían desde tiempo atrás. La adquisición de determinados derechos como los políticos, implicaba para las mujeres la pérdida de su "femineidad". Al abandonar su casa y el cuidado de los hijos, las mujeres perdían así sus virtudes femeninas más esenciales. Se preguntaba la poetisa: "¿Qué resta, pues, para compensación del compañero amargado, cansado, sacudido por todos los disgustos de la calle? ¿Cuál es el porvenir de la familia?" La respuesta a la que llega no carecía de fervor conservador y apocalíptico en varios de sus juicios:

iLíbrenos Dios de la casa cuna oficial al estilo soviético, del interior hogareño fiscalizado y tasado por los gobiernos como en Rusia [...] de la mujer absorta por los reclamos de la lucha para su candidatura $o$ el triunfo de su candidato, y de ese peligro que apenas existe en las clases ricas, pues las madres que rehúyen su misión forman por fortuna una minoría, como la de los criminales o los tarados: el niño en manos ajenas, bajo una vigilancia todo lo competente que se quiera pero sin amor. ${ }^{27}$

\footnotetext{
${ }^{25}$ Mundo Uruguayo, 22 de setiembre de 1932, p. 4.

${ }^{26}$ Mundo Uruguayo, 22 de setiembre de 1932, p. 4.

${ }^{27}$ Mundo Uruguayo, 22 de setiembre de 1932, p. 4.
} 
Se puede ver el miedo a la ruptura del orden social tradicional patriarcal y de paso, el terror que infundía el Estado y su omnipresencia para sustituir a las mujeres en el cuidado de los hijos. Con la equiparación de derechos, "La ternura, la dulzura, todas las aptitudes de la mujer para el suavizamiento de las asperezas y el materialismo desaparecerán en la vorágine. Juana de lbarbourou sintetizaba los temores de un sector de la clase media que temía efectivamente por la disolución de determinados valores, y comparaba esta situación con lo experimentado por los gobiernos revolucionarios de Europa. La prensa conservadora reproducía estos comentarios que luego se reflejaban en las distintas opiniones que emergían en nuestro país.

Ninguna de las medidas tomadas sirvieron para que los acontecimientos políticos no se precipitaran a un quiebre institucional. Desde 1932 Terra ya estaba hablando de un cambio constitucional. Sin demasiadas explicaciones, pero con actos multitudinarios por todo el país, el presidente iba midiendo el ambiente político con propuestas y medidas de efecto. Además, utilizaba su diario "El Pueblo" para afianzar un discurso proclive a su persona, al margen de "El Día", diario histórico del batllismo, del que claramente se quería ir desprendiendo. En la crónica que "El Pueblo" hizo del acto del día de los Trabajadores de 1932, las diferencias quedan claras: "Con todo orden se realizó el desfile por nuestra principal avenida llegando los manifestantes a ocupar algunas cuadras con un total de cinco mil personas [...] entre las que anotamos la presencia de mujeres y niños". ${ }^{28}$ Luego de describir brevemente los actos realizados por los Socialistas, Comunistas y Anarquistas, el diario oficialista culminaba haciendo un análisis de la situación minimizando los actos y evaluando la situación económica de los trabajadores: "Al margen de todo el palabrerío de comunistas, socialistas y anarquistas el pueblo sufre, y sólo espera la salvación de su hambre y su miseria..." 29 El grupo que apoyaba al presidente estaba tomando distancia de los partidos de izquierda, pero, a su vez, ¿no estaba deslizando críticas al Consejo Nacional de Administración al hablar del hambre y miseria? Es cierto que 1932 fue el peor año de la crisis, pero para ser batllista el diario presidencial, podría haber minimizado las críticas.

Las cámaras empresariales y la oposición políica integrada principalmente por el herrerismo y el riverismo colorado se hicieron eco de esta estrategia presidencial, y contribuyeron a presionar a Terra para que se definiera. El diario herrerista "El Debate" decía, el 2 de enero de 1933, criticando las políticas económicas del gobierno: "En quince años de colegialismo, los gastos públicos crecieron en setenta y siete millones de pesos, extraídos sin piedad a la economía nacional extenuada por la sucesión de las imposiciones tributarias". ${ }^{30}$ Ese mes de enero de 1933 no pasaría inadvertido. El presidente Terra concretaría una reunión con Luis Alberto de Herrera en la casa del comerciante herrerista Alberto Puig. Si bien en el momento no se dijo nada expreso sobre dicho encuentro, tiempo después saldría publicado en la prensa la reunión que terminó con el saludo de ambos líderes y la aclaración del jefe blanco: "[...] El cambio radical se impone; hay que hacerlo. Lo haces tú o lo hacemos nosotros. En lo que me es personal, yo ya estoy resuelto" (CAETANO, JACOB, 1991, p.46).

Entre febrero y marzo de 1933 los hechos se fueron precipitando con reuniones y acuerdos entre el presidente y los diferentes sectores de la oposición.

Finalmente y tras ocupar las oficinas públicas e intervenir la empresa de teléfonos y el correo, el presidente emitió un decreto por el cual disolvió las cámaras y el Consejo Nacional de Administración, creó una Junta de Gobierno de nueve miembros con el objetivo de asesorar al Poder Ejecutivo y se fijaba para más adelante la creación de una Asamblea

\footnotetext{
${ }^{28}$ El Pueblo, 2 de mayo 1932, p.2.

${ }^{29}$ El Pueblo, 2 de mayo 1932, p.2.

${ }^{30}$ El Debate, 2 de enero 1933, p.3.
} 
Deliberante que oficiaría como órgano Legislativo. El golpe se concretó el 31 de marzo de 1933, y se iniciaba así la primera dictadura del siglo XX en el Uruguay.

El hecho que marcó el golpe de Estado de Terra fue el suicidio del ex presidente Baltasar Brum. Por sus peculiaridades, no es un caso para ser tratado en este trabajo, pero sin duda marcó un hito en la política nacional.

En abril comenzó la campaña para convocar a una reforma constitucional. Se fijaría una fecha para elegir una Asamblea Constituyente. Esta se encargaría de hacer las modificaciones pertinentes a la Constitución de 1917. En un mensaje radial, el presidente explicó: "Mis ideas reformistas y plebiscitarias, así como los postulados económicos y financieros que vengo pregonando habían encontrado eco simpático y viva repercusión [...] Abandonar esas ideas importaba abandonar la causa del pueblo y hoy la causa del pueblo está en la reforma constitucional, con el plebiscito" (ODDONE, p.131).

A fines de junio se eligió la Asamblea y en agosto se instaló la Constituyente que sería la encargada de la reforma. Tras algunos cambios por el mal funcionamiento de la misma - Terra decidió su disolución y nombrar una "comprimida" de 16 miembros -, el 19 de abril de 1934 se produciría la elección presidencial y el plebiscito confirmatorio de la nueva Constitución.

La nueva Carta Magna consolidaba un Poder Ejecutivo unipersonal, elegido directamente por el pueblo. Las cámaras legislativas serían dos: la de diputados compuesta por 99 miembros e integrada de manera proporcional al número de votos obtenidos por los partidos. La novedad estaba en el Senado, el cual estaría integrado por 30 miembros, divididos en partes iguales entre el partido ganador y el segundo en número de votos. Los cargos en los directorios de las empresas del Estado, la Corte Electoral y los ministerios, también estarían integrados por ambos partidos mayoritarios. El artículo 65 de la constitución, igualaba la ciudadanía para todos los mayores de 18 años de edad, lo que incluía a las mujeres.

Entre el 3 y el 26 de diciembre de 1933 tuvo lugar en Montevideo la VII Conferencia Internacional Americana. Dicha conferencia fue de un valor diplomático fundamental, en el marco de la política exterior de Estados Unidos comprendida por la idea de "buena vecindad" que este país pretendía establecer con el resto de América Latina.

El gobierno de Terra utilizó la VII Conferencia para reposicionar al país en el concierto internacional. Recordemos que el gobierno de Terra estaba en el camino de la consolidación en el marco de la dictadura que se venía ejerciendo desde el 31 de marzo de 1933.

La delegación uruguaya fue presidida por el Dr. Alberto Mañé, ministro de Relaciones Exteriores, el Dr. Mateo Marques Castro, subsecretario del ministerio de Relaciones Exteriores, los senadores blancos Luis Alberto de Herrera y Martín Echegoyen. Fue designada la Dra. Sofía Álvarez Vignoli de Demichelli, esposa del ministro del interior Alberto Demicheli y representante del feminismo uruguayo. Cabe señalar que la participación de Álvarez Vignoli fue relevante en el tratamiento de los derechos políticos y civiles de las mujeres, no sólo en materia política sino también en lo relativo a las aspiraciones aun no conquistadas sobre la patria potestad, disponibilidad de bienes, tutela del marido, padre y hermanos sobre las mujeres, entre otras normas resabios del siglo XIX. En el discurso que dio inicio a la III Comisión dedicada al estudio sobre derechos civiles y políticos de la mujer, Álvarez Vignoli definía al feminismo como "[...] una de esas tantas fuerzas que tienden a conquistar el nivel que por derecho les corresponde. No es la creación caprichosa y antojadiza de almas visionarias, sino que hunde sus raíces en la realidad dolorosa y obscura de la misma vida". ${ }^{11}$ Esta conferencia marcó la vida política de Sofía Álvarez Vignoli, que a instancias del terrismo se iniciaba. Su trayectoria todavía continúa pendiente a ser estudiada desde el punto de vista histórico.

${ }^{31}$ El Pueblo, 17 de diciembre de 1933, p. 8.

14 Revista Estudos Feministas, Florianópolis, 26(2): e48711 
Electo nuevamente presidente, Terra iniciaba así su segunda presidencia esta vez bajo la nueva constitución que junto a los sectores anti batllistas y cámaras empresariales había impulsado. Este período que se iniciaba en 1934 y se extendería hasta 1938 tendría como connotaciones principales la lenta recuperación económica basada en políticas de crecimiento recortando la distribución y las luchas políticas centradas en la abstención electoral de la oposición y los dilemas de esta de cómo enfrentar a la alianza terro-herrerista.

\section{Reflexiones finales}

En las diferentes posturas de los cambios que aparecían sobre las mujeres, podemos ver varias aristas. En primer lugar, que el tema estaba instalado en la agenda pública uruguaya desde principios del siglo XX. Más allá del fracaso que significó la inclusión de los derechos políticos de las mujeres en la constitución de 1917, el tema del sufragio siguió en boga en los cafés, en las organizaciones de mujeres, en la agenda política. En segundo lugar, se hicieron visibles los debates sobre temas generales que marcaban los nuevos espacios que las mujeres iban conquistando. Los cafés, los espacios públicos otrora monopolio masculinos, ahora se veían como lugares compartidos por ambos sexos. Todas estas discusiones y debates que surgieron enriquecieron a ese Uruguay "integrado", en franco crecimiento cultural y político, donde la democracia se venía consolidando y creaba un ambiente de excepcionalidad en América. El ágora ciudadana se veía beneficiada con esos debates y planteos, a pesar de la falta de consensos. Los prejuicios y temores ante los cambios en el statu quo y orden social "natural", generaban dudas en algunos sectores medios y altos de la sociedad. Las opiniones oscilaban entre los cambios radicales y graduales, los nuevos roles que destruían los valores tradicionales y la organización familiar tradicional e incluso, las virtudes y valores morales que la "naturaleza" había dado a cada uno de los sexos. No olvidemos también los argumentos políticos que estaban teñidos no sólo de concepciones ideológicas generales propias de la cultura de la época, sino también por cuestiones partidarias.

Tras la aprobación de los derechos, comenzó una larga reivindicación política sobre la apropiación de la autoría de estas concesiones. En el Uruguay partidocéntrico, los derechos políticos de las mujeres no podían estar por fuera de su influencia y aprobación. Los partidos se convirtieron en los instrumentos por los cuales los reclamos de los grupos feministas fueron escuchados y traducidos en derechos. Pero, además, parecían ser fruto de necesidades electorales de una coyuntura política y económica desfavorable.

\section{Referências}

BARRÁN, José Pedro; NAHUM, Benjamín. Batlle, los estancieros y el imperio británico, t. 2 "Un diálogo difícil". Montevideo: Ediciones de la Banda Oriental, 1985.

BARRÁN, José Pedro. Los conservadores uruguayos 1870-1933. Montevideo: Ediciones de la Banda Oriental, 2004.

CAETANO, Gerardo; JACOB, Raúl. El nacimiento del terrismo (1930-1933), tomo 1. Montevideo: Ediciones de la Banda Oriental, 1989.

CAETANO, Gerardo; JACOB, Raúl. El nacimiento del terrismo, tomo 3, "El golpe de Estado". Montevideo: Ediciones de la Banda Oriental, 1991.

CAETANO, Gerardo; PÉREZ, Romeo; RILLA, José. "La partidocracia uruguaya. Historia y teoría de la centralidad de los partidos políticos". Cuadernos del CLAEH, Montevideo, n. 44, 1987.

CAETANO, Gerardo; ROGER, Geymonat. La secularización uruguaya (1859-1919), Tomo 1 , Catolicismo y privatización de lo religioso. Montevideo: Taurus, 1997. 
DE AZÚA, Carlos Real. Uruguay ¿Una sociedad amortiguadora? Montevideo: Ediciones de la Banda Oriental, 2000.

LAVRIN, Asunción. Mujeres, feminismo y cambio social en Argentina, Chile y Uruguay 1890 1940. Santiago de Chile: Centro de Investigaciones Diego Barros Arana, 2005.

LÓPEZ D'ALESSANDRO, Fernando. Historia de la izquierda uruguaya, v.3, "La fundación del Partido Comunista y la división del Anarquismo 1919-1923". Montevideo: Editorial Vintén, 1992.

OSTA, Laura. El sufragio. Una conquista femenina. Montevideo: OBSUR, 2008.

ODDONE, Juan. Uruguay entre la depresión y la guerra 1929-1945. Montevideo: Fundación de Cultura Universitaria, 1990.

PEDRO, Joana Maria. "Translating the debate: the usage of gender category in the historical research". História, São Paulo, v.24, n. 1, p.77-98, 2005.

RAMA, Carlos. "Obreros y Anarquistas". Revista Enciclopedia Uruguaya, Montevideo, n.32, 1969.

RODRIGUEZ VILLAMIL, Silvia; SAPRIZA, Graciela. "Feminismo y Política. Un análisis crítico del proceso de aprobación del voto femenino en el Uruguay". Hoy es Historia, Montevideo, Año I, n. 4, junio-julio 1984.

THÉBAUD, Françoise: "La Primera Guerra Mundial: ¿la era de la mujer o el triunfo de la diferencia sexual?". En: DUBY, Georges; PERROT, Michelle (dir.). Historia de las Mujeres. EI siglo XX Guerra, entreguerra y posguerra, t.9. Madrid: Taurus, 1993.

\section{Prensa}

El Bien Público (Montevideo) 1932.

El Demócrata (Montevideo) 1919.

El Día (Montevideo) 1932.

El País (Montevideo) 1921.

El Pueblo (Montevideo) 1932.

El Pueblo (Montevideo) 1933.

El Siglo (Montevideo) 1924.

La Batalla (Montevideo) 1917.

Mundo Uruguayo (Montevideo) 1925.

Mundo Uruguayo (Montevideo) 1932.

Justicia (Montevideo) 1923.

Justicia (Montevideo) 1924.

\section{Diarios de Sesiones Palacio Legislativo}

Diario de Sesiones de la Cámara de Representantes, tomo 381, p. 126 (Sesión del 14 y 15 de diciembre de 1932).

[Recebido em 25/01/2017,

reapresentado em $21 / 02 / 2018$

e aprovado em 27/02/2018]

Women and their Spaces: Parties, Rights and Debates in Uruguay of 1920 and 1938 Abstract: This article is a descriptive synthesis of the historical context centered on the discussions about the different positions in the approval of the political rights of women in Uruguay from 1920 to 1938. From women's history, this study proposed to report new historical discourses where women and their actions were equitably represented in the history of men. In the process of consolidating Uruguay as a "model country" created under the aegis of Batllism, the political

16 Revista Estudos Feministas, Florianópolis, 26(2): e48711 
parties were presented as the main instruments, which transmitted the changes according to their specific electoral and political interests. In discussions about the values that characterized Uruguay, the issue of women's political rights was present. The parties have taken women as a political object as one of the axes of this democratic and social consolidation.

Keywords: Feminism; Women political rights; Parties

María Laura Osta Vázquez (lauraosta@hotmail.com) es Investigadora Nivel 1 ANII, Docente Universidad de Montevideo, Docente Flacso-Uruguay. Doctora en Historia Cultural por la UFSC-Brasil, realiza su post-doctorado en Historia de la Infancia. Profesora de Historia por la Universidad de Montevideo, investigadora Nivel 1 da ANII. Profesora orientadora en Flacso-Uruguay. Publicó varios artículos en revistas arbitradas. Presentó diversas exposiciones de trabajos en congresos y coloquios uruguayos e internacionales. Orientó 6 teses de máster y 3 de estudiantes de licenciatura. Coordinó una mesa de trabajo en un coloquio internacional, y organizo un congreso internacional. Ganó diversos premios y becas, entre ellos, en el año 2015, el Premio Elsa Chaney, de LASA. En diciembre 2016 publicó su último artículo en la Revista de la Facultad de Derecho de la UDELAR.

Álvaro García Alonso (alv_gar_al@yahoo.com.ar) es Profesor de Historia por el Instituto de Profesores Artigas. Estudiante de Máster en Historia Social e Cultural por la Universidad de Montevideo. Profesor de liceo en colegios públicos y privados. Publicaciones en coautoría de libros para educación primaria.: "Área de Conocimiento Social 4"; "Área de Conocimiento Social 5" y "Área de Conocimiento Social 6", editorial SM, Montevideo, 2012. "iQué lindo vivirlo! Una historia del Juan XXIII en sus 50 años", Editorial Juan XXIII, Montevideo, 2014. "Las distintas y Olvidadas", Revista Estudos Feministas, Abr 2016, v. 24, n. 1, p.365-367. 